REVIEW ARTICLE

\title{
Preconceptional and Antepartum Assessment of Patients with a Previous Cesarean Section
}

\author{
Bernat Serra ${ }^{1}$, Alberto R Melcón ${ }^{2}$, Mireia Gutierrez ${ }^{3}$
}

\begin{abstract}
Cesarean section (CS) is the most frequently performed surgical procedure around the world and during the last decades, the incidence of CSs has continuously risen in both, developed and developing countries. Consequently, women with a previous CS becoming pregnant again is constantly growing. This article aims to clarify how women who have had a previous CS should be counseled and managed, either before getting again pregnant or during pregnancy with regard to the different complications related to this previous surgical procedure.

Keywords: Cesarean scar pregnancy, Cesarean section, Placenta accreta, Placenta previa, Preconceptional counseling, Uterine rupture, Uterine scar defect, Vaginal birth after cesarean.

Donald School Journal of Ultrasound in Obstetrics and Gynecology (2021): 10.5005/jp-journals-10009-1698
\end{abstract}

\section{INTRODUCTION}

Cesarean section (CS) is the most frequently performed surgical procedure around the world, with $>18.5$ million procedures done every year. ${ }^{1}$ Moreover, during the last decades, the incidence of CSs has continuously risen in both, developed and developing countries, with many of them having nationwide CS rates $>30 \%$. As a result of these high primary CS rates, the incidence of women with a previous CS who want to or become pregnant again is also growing worldwide. This article aims to clarify how women who have had a previous CS should be counseled and managed either before getting again pregnant or during pregnancy.

\section{Preconceptional Assessment and Counseling}

There is no doubt that preconceptional assessment of women with a previous CS gives the opportunity to: (1) inform about the implications of a previous cesarean on the next pregnancy; (2) customize the risk; (3) implement strategies to reduce the risk of complications; (4) establish the prognosis for vaginal delivery in a future gestation.

\section{Implications of a Previous Cesarean Section}

A previous CS has been considered many years ago as a risk factor in a subsequent pregnancy, especially for repeat CS and for intrapartum uterine rupture. But nowadays it is also known that having had a CS increases the risk of abnormal placentation like placenta previa, placenta accreta, abruption, or scar pregnancy if the woman becomes pregnant again. Even more, some recent studies have shown that a previous CS increases the risk of having an unexplained stillbirth by as much as $23-40 \%$, being the excess risk from 34 weeks of gestation onward. ${ }^{2,3}$ There is also evidence that having a previous CS increases the likelihood of fertility problems. ${ }^{4,5}$

\section{Customizing the Risk}

Risk of Placenta Previa/Accreta

Previous cesarean delivery, especially prelabor cesarean delivery is a risk factor for abnormal placentation in future pregnancies. ${ }^{6}$ Abnormal placentation has been associated with both, maternal
${ }^{1-3}$ Department of Obstetrics, Gynecology and Reproductive Medicine, Dexeus University Hospital, Barcelona, Spain

Corresponding Author: Bernat Serra, Department of Obstetrics, Gynecology and Reproductive Medicine, Dexeus University Hospital, Barcelona, Spain, Phone: +34 628901 038, e-mail: berser@dexeus.com How to cite this article:Serra B, Melcón AR, Gutierrez M. Preconceptional and Antepartum Assessment of Patients with a Previous Cesarean Section. Donald School J Ultrasound Obstet Gynecol 2021;15(2): $160-168$.

Source of support: Nil

Conflict of interest: None

and neonatal morbidity. These include the need for antepartum hospitalization, preterm delivery, emergent cesarean delivery, hysterectomy, blood transfusion, surgical injury, intensive care unit (ICU) stay, and fetal and maternal death. To effectively counsel women about their risk of complications due to the placenta in future pregnancies, it is essential to have a clear understanding of the incidence of these potentially life-threatening complications in women with prior cesarean delivery.

The risk of placenta previa increases with an increasing number of previous CSs as presented in Table 1.,8

\section{Risk of Placental Abruption}

The incidence of placental abruption with any prior CS is estimated to be between $1.2 \%$ and $1.5 \% .^{9,10}$ It remains unclear whether the risk increases with an increasing number of previous CSs.

Table 1: Impact of the number of previous cesarean sections on the incidence of placenta previa and accreta in a subsequent pregnancy

\begin{tabular}{lll}
\hline & Previa (\%) & Accreta if previa (\%) \\
\hline No previous CS & 0.25 & 3.3 \\
1 CS & 0.65 & 11 \\
2 CS & 1.7 & 40 \\
3 CS & 3.3 & 61 \\
$\geq 4$ CS & 10 & 67 \\
\hline
\end{tabular}

Incidence of placenta previa and accreta according to the number of previous cesarean sections

(c) Jaypee Brothers Medical Publishers. 2021 Open Access This article is distributed under the terms of the Creative Commons Attribution 4.0 International License (https://creativecommons.org/licenses/by-nc/4.0/), which permits unrestricted use, distribution, and non-commercial reproduction in any medium, provided you give appropriate credit to the original author(s) and the source, provide a link to the Creative Commons license, and indicate if changes were made. The Creative Commons Public Domain Dedication waiver (http://creativecommons.org/publicdomain/zero/1.0/) applies to the data made available in this article, unless otherwise stated. 


\section{Risk of Uterine Rupture}

Uterine rupture is a potentially life-threatening complication that has been directly attributed to vaginal birth after cesarean (VBAC) and its incidence in women who attempt labor after a transverse lower uterine segment incision is $0.2-1.5 \%$ and $1-1.6 \%$ if the incision was longitudinal but also in the lower uterine segment. ${ }^{11}$ It is known that the risk of uterine rupture is especially increased in the case of previous classical (longitudinal) or inverted T incision (4-9\%), previous uterine rupture, or previous hysterotomy or myomectomy entering the uterine cavity. Estimating the risk of uterine rupture for women with a prior cesarean has been challenging not only because studies report on actual rather than the intended route of delivery but also because studies often mixed true anatomic ruptures with asymptomatic dehiscences. The combined risk of uterine rupture for women undergoing a trial of labor after cesarean (TOLAC) is estimated to be 0.47 and $0.026 \%$ for women undergoing an elective repeat cesarean section (ERCS). ${ }^{12,13}$ Compared with women undergoing an elective repeat cesarean delivery (ERCD), women undergoing a TOLAC have a significantly higher risk of uterine rupture (RR 20.74; $p<0.0010$ ). Using $0.026 \%$ as the baseline risk for ERCD, the calculated risk difference is $0.51 \%$ translating to 5.1 additional ruptures per 1,000 women undergoing TOL. Although the incidence of maternal death reported because of uterine rupture is very low, the risk of perinatal death due to this complication is estimated to be $6.2 \%$. Moreover, the risk of hysterectomy due to uterine rupture is an important consideration for women planning VBAC, with rates ranging from 14 to $33 \%$ in case of rupture.

Conversely, in the case of a previous cesarean with segmental incision, the risk of uterine rupture decreases after the first successful VBAC: $1.6,0.3,0.2$, and $0.35 \%$ after $0,1,2$, and 3 VBAC, respectively. ${ }^{14}$

Factors that have been related to an increased risk of uterine rupture and the respective odds ratio are:

- Advanced maternal age ( $\geq 40$ years): 2.8 (1.6-20.3). ${ }^{15}$

- Number of previous cesarean deliveries. 2 vs 1: 4.8 (1.8-13.2); 2 or more: 5.3 (2.1-12.9). ${ }^{16}$

- Inter-delivery interval. Whereas some studies have found increased rates of uterine rupture with intervals $<24$ months: OR 2.05 (1.41-2.96) or $1.9 \%$ compared to $1.3 \%$, and $<18$ months: OR $2.4(1.0-5.6)$ or $4.8 \%$ compared to $1.3 \%$, another did not found differences even with intervals $<12$ months. ${ }^{17-19}$

In its turn, contradictory data are available regarding the influence of the number of suture layers in the previous hysterotomy closure. Whereas a single- or a double-layer suture during the previous CS does not seem to have an impact on the incidence of uterine rupture in one study, the OR for uterine rupture when a single-layer suture was used is $2.69(1.37-5.28)$ in another one. ${ }^{20,21}$ On the other hand, a review of 2,142 women who underwent a TOLAC showed an increased risk of uterine rupture when a 1-layer interlocking closure had been used when compared with a 2-layer closure. $^{22}$

Another factor that affects the risk of uterine rupture is having had a previous cesarean delivery with severe postpartum hemorrhage: it increases the likelihood of uterine rupture with an adjusted OR of $5.6(2.4-13.2){ }^{23}$

Recent studies have shown that the presence of uterine scar defects on ultrasound studies performed in the non-pregnant state is related to a higher risk of uterine rupture, especially if the defect is large. ${ }^{24}$ There is some consensus to define myometrial scar defects according to the thickness of the remaining myometrium: defects are considered small when the remaining thickness of the myometrial layer is $>2.5 \mathrm{~mm}$ and large if it is less. Pictures of a normal scar, small defect, large defect, and uterine rupture are shown in Figure 1. If the ultrasound study is not conclusive, magnetic resonance (MR) may be used (Fig. 2). The only reported risk factor for scar defects found in a systematic review was the occurrence of more than one previous cesarean [OR: $2.24(1.13,4.45), p=0.02]{ }^{24}$

According to the blinded study performed by Vikhareva Osser and Valentin on 162 women who had a transvaginal ultrasound done at 4-6 months after cesarean, the incidence of uterine rupture and uterine dehiscence during TOLAC in women with a small defect (myometrial thickness $>2.5 \mathrm{~mm}$ ) is low (2.2\%), compared to that of women with large scar defects (23.1\%). ${ }^{25}$ In this same study, $75 \%$ of women with a normal scar had a vaginal delivery, whereas the incidence dropped to $50 \%$ and $40 \%$ in women with small and large defects, respectively. As most women with large defects are symptomatic, it seems reasonable to recommend a transvaginal ultrasound exploration to women with two previous CS or to those with one previous CS with intermenstrual spotting/bleeding. If a large defect is found and the woman is not symptomatic, the defect does not need to be repaired but the woman should be counseled to have an early first-trimester ultrasound done to discard a scar pregnancy in the next pregnancy and to deliver by elective CS.

\section{Implementing Strategies to Reduce the Risk of Complications}

The evaluation of women with a previous CS in the non-pregnant state allows to evaluate the factors previously mentioned in this article and reduce the risks by delaying pregnancy if the previous CS is recent and by recommending an ultrasound exploration if the women have had $>2$ CS or is symptomatic. Although the laparoscopic repair of large defects is not mandatory, it should be discussed with the patient if she has pain or intermenstrual bleeding, or before trying to become pregnant again to reduce the risk of a cesarean scar pregnancy (CSP). According to our experience, the laparoscopic repair of the scar defect eliminates symptoms in almost all women and manages to eliminate the defect in $80 \%$ of cases, thus reducing the risk of a scar pregnancy.

\section{Establishing the Prognosis for a Vaginal Delivery in a Future Gestation}

After a first CS, most women are concerned about having to undergo another cesarean in their subsequent pregnancy. Depending on the primary indication, e.g., a previous multiple myomectomy, classical incision, uterine rupture, etc., a recurrent CS can be anticipated. But for most primary indications, subsequent vaginal delivery is possible, and the likelihood may be calculated based on different factors. Most algorithms include the following factors to establish a prognosis of vaginal delivery in a subsequent trial of labor: age, body mass index (BMI), race, recurrent primary indication, and previous vaginal delivery. ${ }^{26-28}$

Increasing maternal age and BMI decrease the chance of having a subsequent vaginal delivery whereas having had a prior vaginal delivery, both before and after the previous cesarean, increases the chance to give birth vaginally. Using the simple predictive graphic nomogram proposed by Landon for the probability of vaginal birth delivery resulting from TOLAC, the $\%$ of vaginal delivery can easily be calculated. ${ }^{27}$ The different algorithms should nevertheless be 
used with caution since they cannot be directly extrapolated to other populations, especially when the overall CS rate is different.

\section{Prenatal Assessment}

Once a woman with a previous CS becomes pregnant again, the main objective of the prenatal/antepartum assessment is to detect and/or predict possible complications related to this condition. These are mainly:

- CSP.

- Placenta previa.
- Placental accretism.

- Uterine rupture.

\section{Cesarean Scar Pregnancy}

Cesarean scar pregnancy (CSP) is a rare but very serious complication of pregnancy, consisting of the implantation of the gestational sac on the hysterotomy scar (Figs 3 and 4). This condition is increasing in frequency as the incidence of CS does and often poses a diagnostic challenge. Its incidence is estimated to be $1 / 1,800$ pregnancies in women with a previous CS, although in our hospital, the Dexeus University Hospital of Barcelona, it has
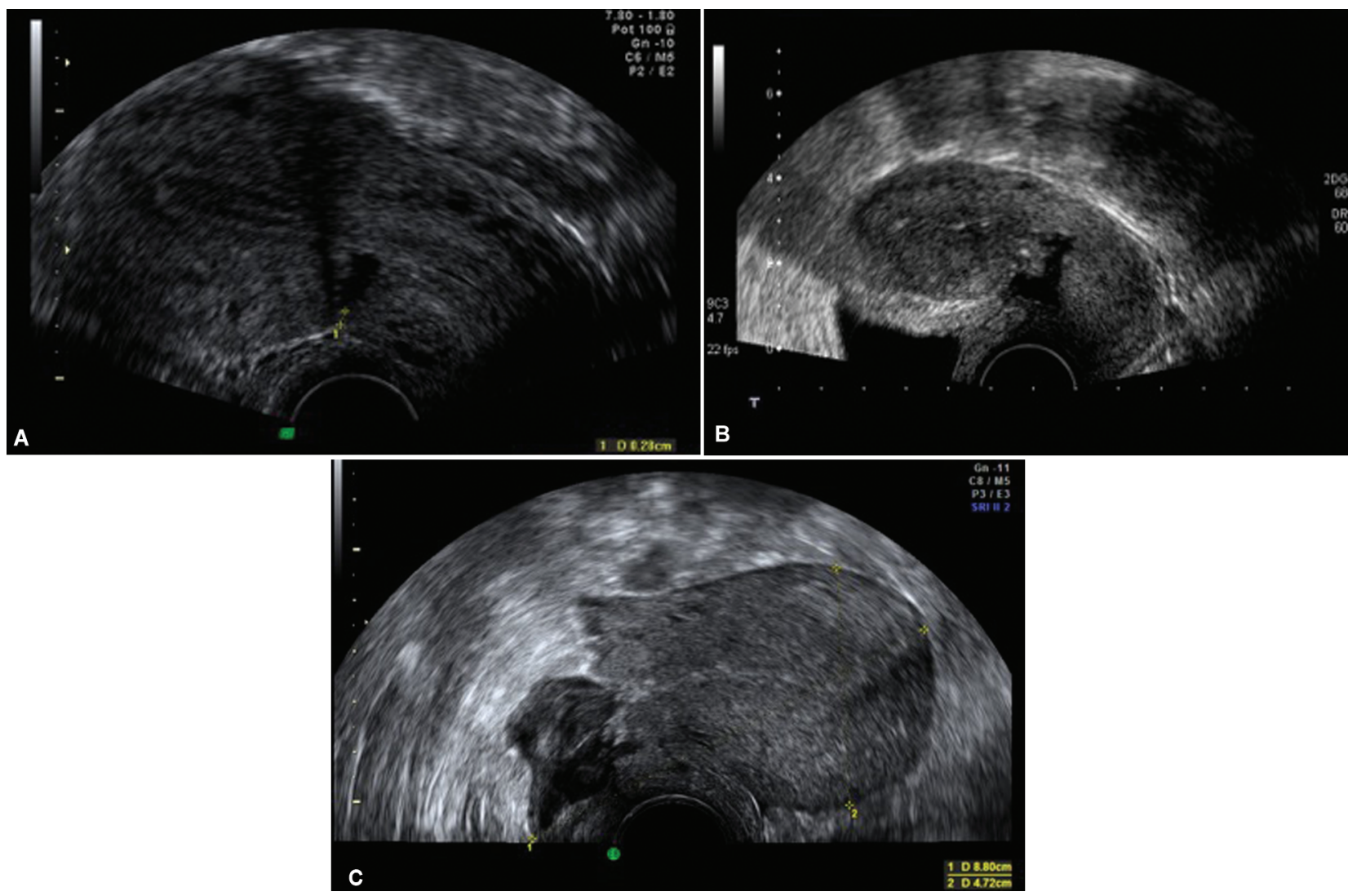

Figs 1 A to C: (A) Small defect; (B) Large defect; (C) Uterine rupture
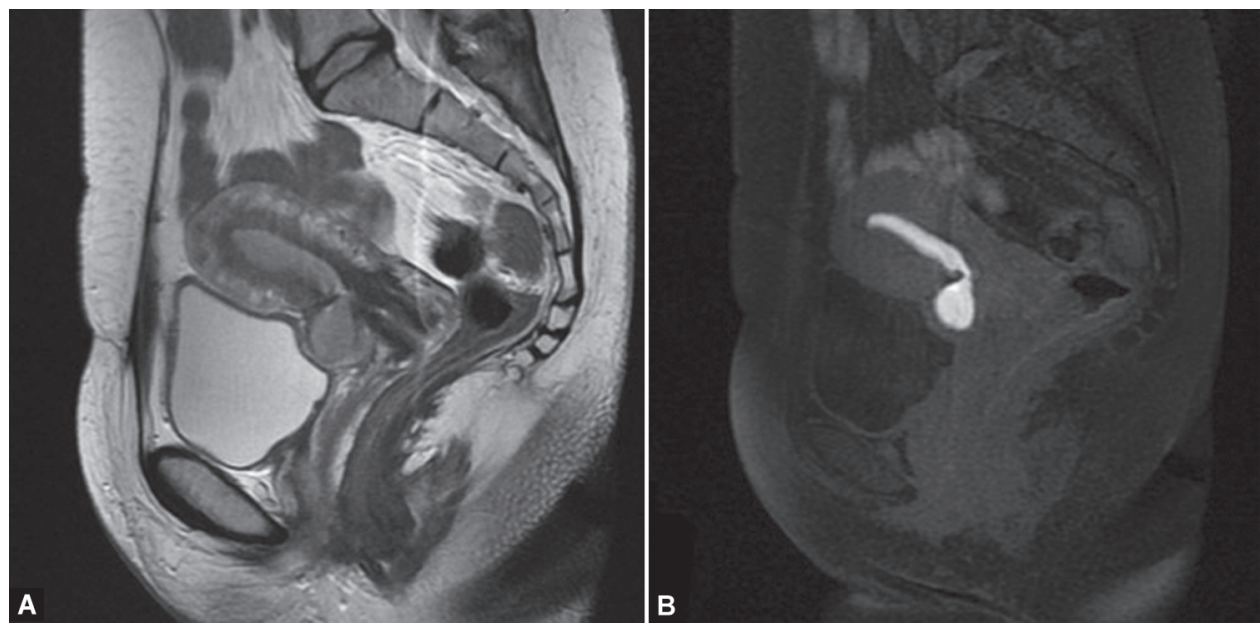

Figs $2 A$ and B: (A) T2 enhanced magnetic resonance of a cesarean scar defect in the menstrual phase; (B) T1 enhanced magnetic resonance of a cesarean scar defect in the menstrual phase 


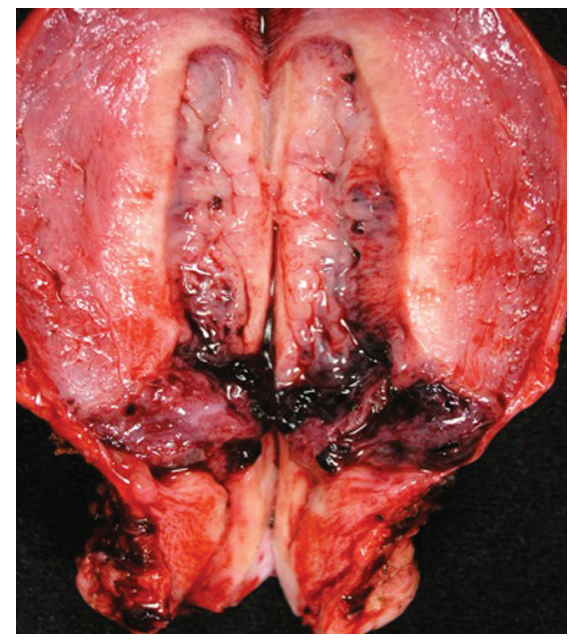

Fig. 3: Longitudinal view of the uterus with a cesarean scar pregnancy

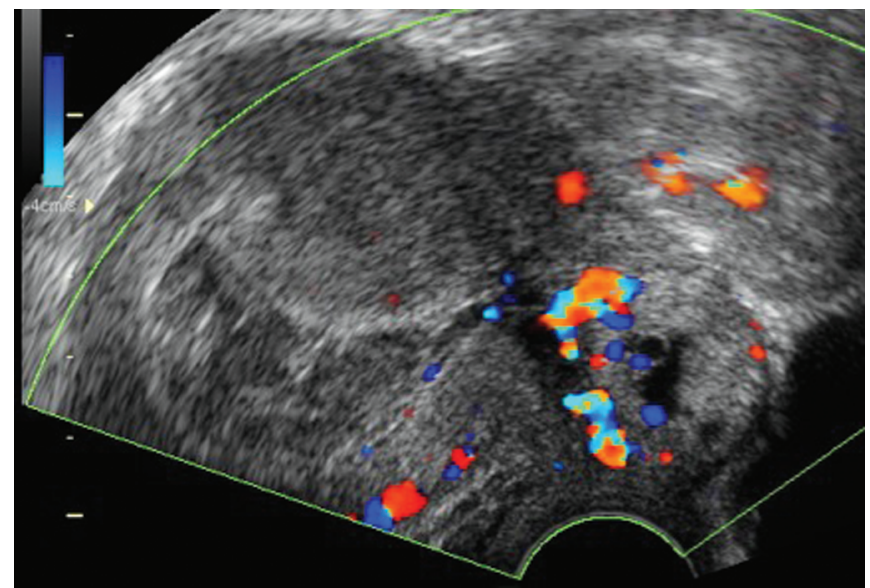

Fig. 5: Longitudinal sagittal ultrasound plane of the uterus with a scar pregnancy

been slightly higher during the last 10 years: $1 / 1,450$. The risks associated with this condition make it advisable to perform an early first-trimester ultrasound on all women with a previous CS, but it must be done if the woman has $\geq 2$ previous $C S$ or has been diagnosed with a uterine scar defect.

Its diagnosis is dependent on the visual assessment of the longitudinal sagittal ultrasound plane of the uterus (Fig. 5). Misdiagnosing a low intrauterine chorionic sac as a CSP, or a true scar pregnancy as an intrauterine pregnancy (IUP), may lead to severe adverse outcomes including hysterectomy or even the death of the woman.

In a retrospective review of 57 cases of CSP and 185 normal intrauterine pregnancies, the authors found that on a first-trimester ultrasound performed between 5 weeks and 10 weeks of gestation, the relative location of the center of the gestational sac to the midpoint of the uterus along a longitudinal line between the external cervical os and the fundus, had a sensitivity of $93.0 \%$ and specificity of $98.9 \%$ if it was below the midpoint ${ }^{29}$ (Fig. 6).

The differential diagnosis between a CSP and a cervical pregnancy may be especially difficult, and one of the signs that may be helpful to differentiate those pregnancies with the worse outcome is the myometrial thickness at the scar. If it is $<5 \mathrm{~mm}$, the risk of placenta increta or percreta is very high.

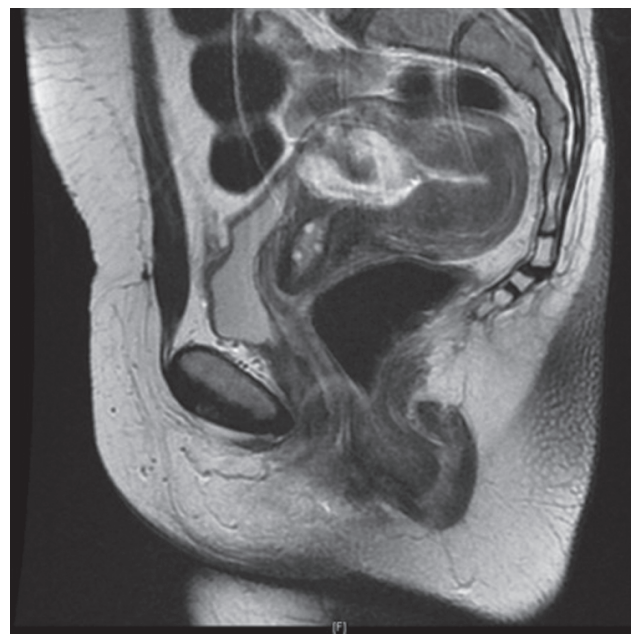

Fig. 4: Magnetic resonance of a cesarean scar pregnancy

Expectant management of CSP with no cardiac activity may be a reasonable option in view of the low likelihood of maternal complications requiring intervention, although close surveillance is advisable to avoid adverse maternal outcome. ${ }^{30}$ If no embryo is seen at the moment of the diagnosis, ultrasound exploration and hCG levels should be done every 2-3 days to follow-up the patient for at least 3 scans or until 7 weeks by reliable dating. Then, hCG should be followed until zero and the last ultrasound done at that moment.

If the CSP is a viable one with a positive fetal heartbeat, available evidence-based counseling should be done. If the patient requests termination of pregnancy, this should be done without delay. If the woman does not want to become pregnant again, a hysterectomy could be considered. On the other hand, if she expresses the desire to preserve fertility, a conservative treatment option should be chosen. The literature supports an interventional rather than medical approach. According to a recent systematic review of treatment studies, five approaches for treating CSP are recommended, depending on availability, the severity of patient symptoms, and surgical skills: (1) resection through a transvaginal approach, (2) laparoscopy, (3) uterine artery embolization in combination with dilatation and curettage and hysteroscopy, (4) uterine artery embolization in combination with dilatation and curettage, and (5) hysteroscopy. ${ }^{31}$ On the other hand, another systematic review published the same year observed the following success rates: systemic methotrexate: $8.7 \%$, uterine artery embolization: $18.3 \%$, hysteroscopy: $39.1 \%$, dilatation and curettage: $61.6 \%$, and hysterotomy: $92.1 \%$, with respective hysterectomy rates of 3.6, 1.1, 0.0, 7.3, and $1.7 \% .{ }^{32}$ Systemic methotrexate and dilatation and curettage are not recommended as first-line treatments as these are associated with high complication and hysterectomy rates. A more recently proposed treatment consists in the placement and inflation of intrauterine/intracervical balloon catheters. ${ }^{33}$

If the woman expresses her desire of continuing pregnancy, she should be informed that expectant management may achieve live birth rates around $50-60 \%$, but with an over $60 \%$ risk of having to undergo a hysterectomy because of placental implantation anomalies or second-trimester uterine rupture. ${ }^{34}$

\section{Placenta Previa}

As previously mentioned in this chapter, the incidence of placenta previa increases with an increasing number of previous CS (Table 1). 

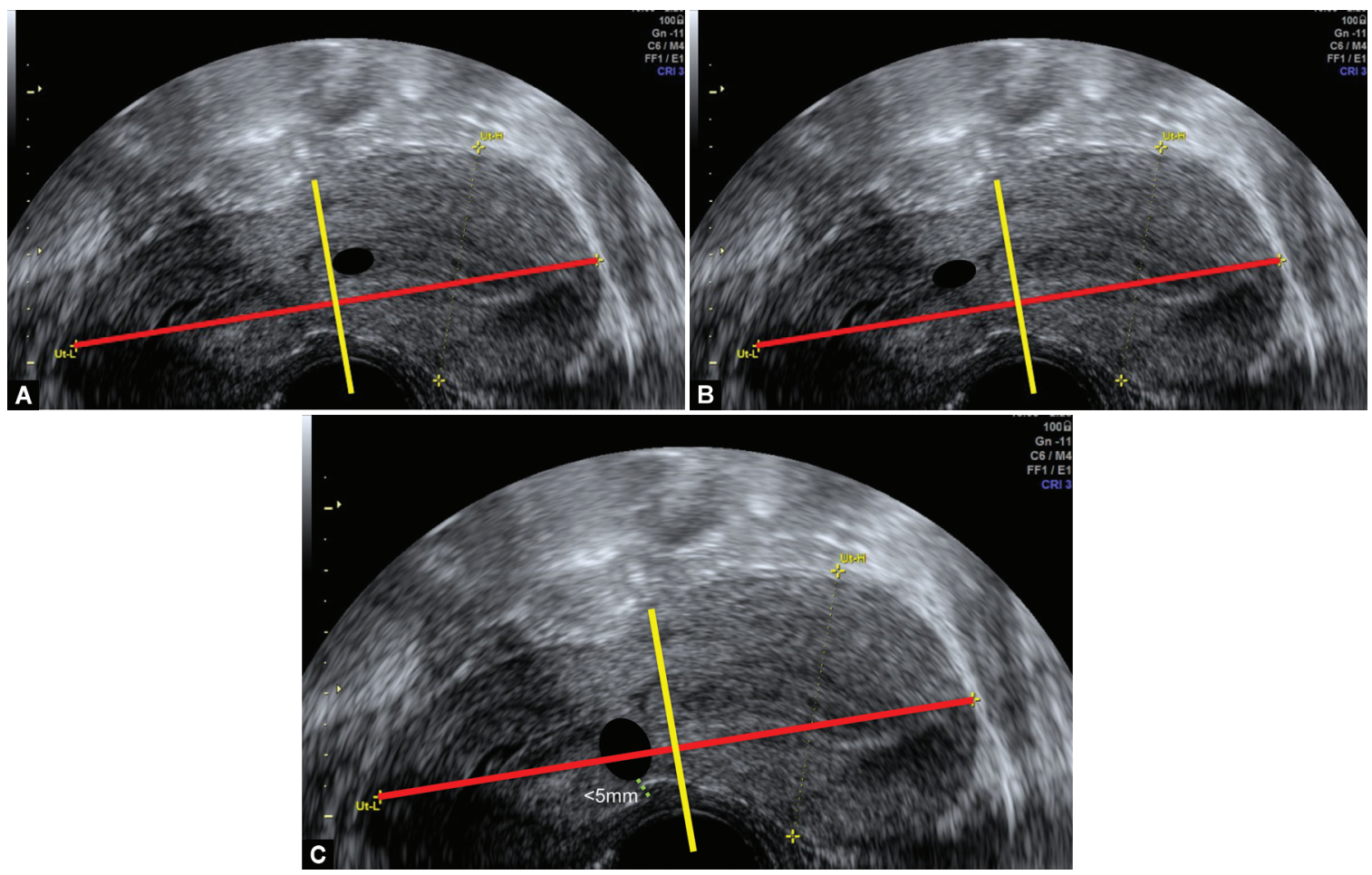

Figs $6 \mathrm{~A}$ to C: Relative location of the center of a simulated gestational sac to the midpoint of the uterus along a longitudinal line between the external cervical os and the fundus: (A) If the sac is above the imaginary line that divides the uterus in the upper and lower half, it is mostly a normal intrauterine pregnancy; (B) If the sac is below the line, suspect a cesarean scar pregnancy or a cervical pregnancy; (C) If the sac appears to be embedded in the myometrium with a remaining myometrial thickness $<5 \mathrm{~mm}$, consider it as a cesarean scar pregnancy

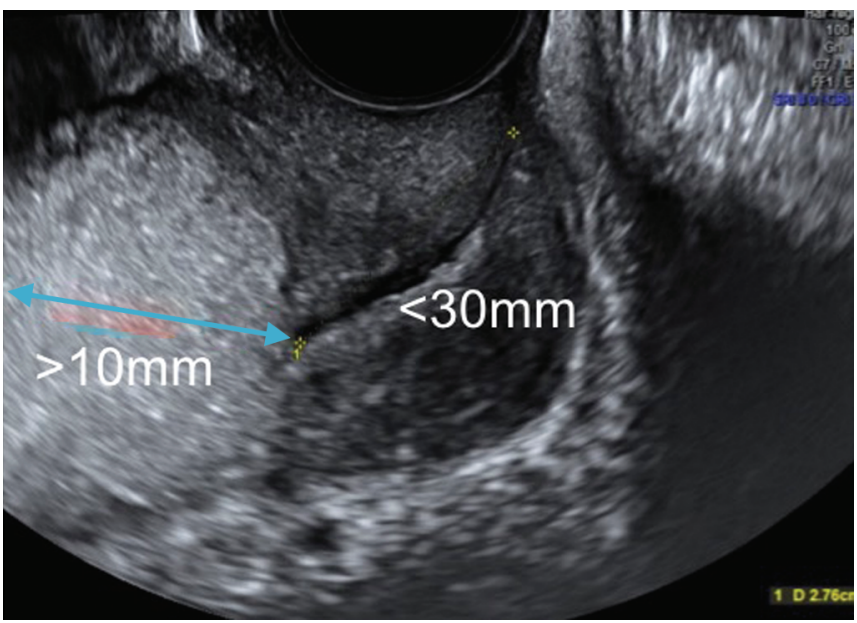

Fig. 7: Specific ultrasonographic signs proposed to manage pregnancies with placenta previa: cervical length and placental thickness over the internal cervical os

In its turn, placenta previa is a high-risk factor for massive PPH, thus increasing the incidence of blood transfusions and cesarean hysterectomies. $^{35,36}$

Once a cervical or CSP has been ruled out at the first trimester, placenta previa may be discarded during the second one. In turn, the presence of a placenta previa in these patients requires careful evaluation of possible signs of abnormal placentation as discussed at length in the next paragraph of this article.

If a placenta previa is found during the second-trimester scan, a new ultrasound should be scheduled at 28-32 weeks to confirm the diagnosis of placenta previa with or without placenta accreta or to rule out a marginal/low lying placenta or vasa previa. If the diagnosis of placenta previa with or without placenta accreta is confirmed, serial measurements of the cervical length $(C L)$ and the placental thickness (PT) over the cervical os have recently been proposed to manage these patients (Fig. 7). ${ }^{37}$ Accordingly, if $\mathrm{CL}$ remains $>30 \mathrm{~mm}$ and $\mathrm{PT} \leq 1 \mathrm{~cm}$ at these controls, conservative outpatient management with delivery at 37-38 weeks could be considered. On the contrary, if CL is or drops $\leq 30 \mathrm{~mm}$ or PT is $\geq 1 \mathrm{~cm}$, the administration of steroids should be considered to accelerate fetal lung maturation and the patient is counseled to stay near to a reference center. Finally, if $C L$ is or drops $\leq 10-15 \mathrm{~mm}$, consider in-patient management and delivery by 34-35 weeks. Such a short $\mathrm{CL}$ is related to an increased risk of placenta accreta.

\section{Placental Accretism}

The presence of a CS scar constitutes nowadays the main risk factor for morbidly adherent placenta (MAP) and a coexisting placenta previa increases dramatically the risk of this complication. ${ }^{38}$ Furthermore, women with a history of previous cesarean delivery presenting with a placenta previa have become the largest group with the highest risk for placenta previa accreta. In a recently published review of almost 3,900 pregnancies presenting with placenta previa or low-lying placenta and 1 or more prior cesarean deliveries, the authors found an overall incidence of placenta previa accreta of $8.4 \%$, being three times higher in those women with 2 or more previous CS (13.3\%) when compared with those with only one previous CS (4.1\%). ${ }^{39}$

The concept of MAP encompasses a spectrum of conditions characterized by abnormal adherence of the placenta, with three major variants according to the degree of trophoblastic invasion 


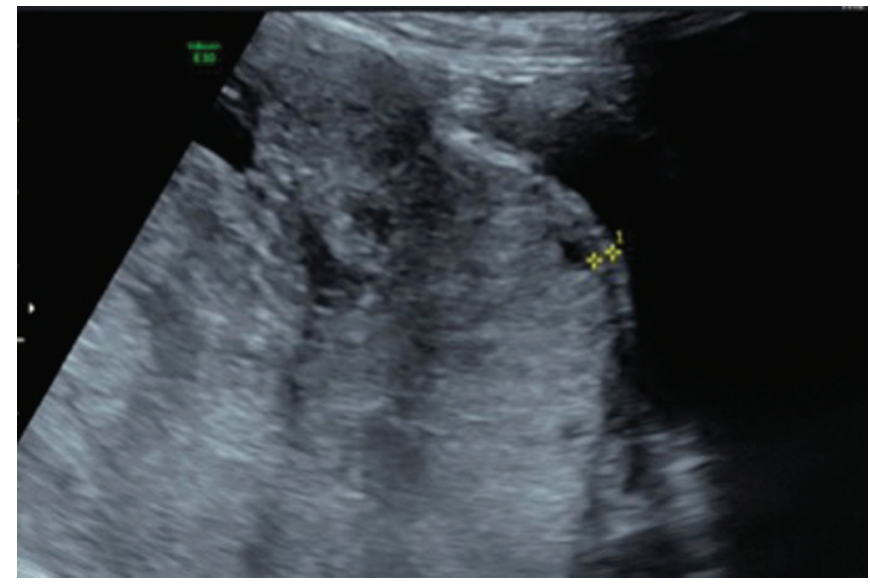

Fig. 8: Image showing a placenta previa in a scarred uterus with intraplacental lacunae, loss of hypoechoic retroplacental space, and reduced myometrial thickness

through the myometrium and uterine serosa: placenta accreta, increta, and percreta, and ultrasound is the primary method for diagnosing these conditions. In women at risk, ultrasound signs of MAP should be sought to start in the second trimester, and from 28 weeks of gestation onward, serial follow-up scans are recommended to accurately predict the extent of the invaded area and to plan the best surgical treatment. If the ultrasound examination is inconclusive, magnetic resonance imaging (MRI) should be considered to assess the degree of invasion, especially if the involvement of adjacent organs is suspected.

The proper assessment of the presence and degree of placental invasion requires the visualization of the sagittal plane of the lower uterine segment and bladder, the latter being partially full to better delineate its relationship with the uterus and placental tissue. The main ultrasonographic signs of MAP are (Figs 8 and 9): ${ }^{40}$

- Intraplacental lacunae.

- Loss of hypoechoic retroplacental space.

- Reduced myometrial thickness: a myometrial thickness $<1 \mathrm{~mm}$ practically confirms the existence of accretism.

- Bladder wall abnormalities including focal defects in the echogenic bladder border or bulging of the bladder itself, induced by aberrant vessels running at the bladder-uterus interface. In cases of placenta percreta, exophytic masses inside the bladder may be visualized.

- Doppler abnormalities: placental vascular flow, increased subplacental vascularity, bladder-uterine interface hypervascularity, vessels extending from the placenta to the bladder, and vessels crossing the interface disruption site.

\section{Uterine Rupture}

A uterine rupture is a rare event that occurs when a full-thickness disruption of the uterine wall that also involves the overlying visceral peritoneum (uterine serosa) is present. Most uterine ruptures are associated with a trial of labor in a uterus with a surgical scar from previous surgery, most often after cesarean delivery and it frequently results in life-threatening maternal and fetal compromise (hysterectomy $14-33 \%$; maternal death $0.21 \%$; neonatal death $5 \%$; severe neonatal neurologic morbidity $6-8 \%)^{12,41}$

Despite its low incidence, concerns about this complication have led to a decline in attempted vaginal birth after CS, with a

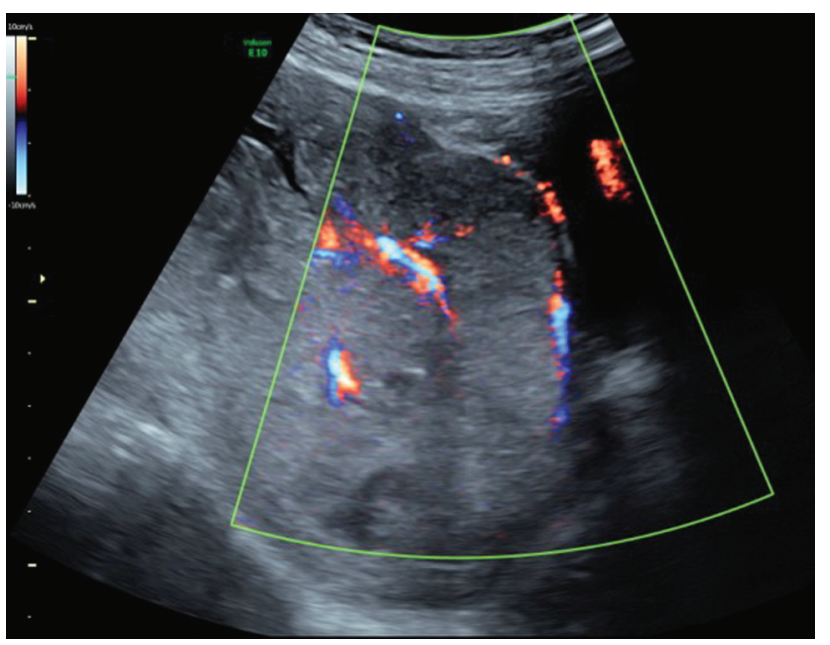

Fig. 9: Image showing placental vascular flow and bladder-uterine interface hypervascularity

simultaneous rise of cesarean rates. A 2008 meta-analysis concluded that TOLAC was associated with a success rate of $73 \%$ and the maternal morbidity was similar in women experiencing TOLAC and women choosing ERCD. However, the meta-analysis did a further comparison between failed vs successful VBAC as well as ERCD and it determined that women who experienced failure of VBAC presented an increased risk of maternal adverse outcomes $(3.8 \%$ of maternal morbidity), compared with both latter groups $(0.2 \%$ in women who have VBAC and $0.8 \%$ in women who undergo ERCD). ${ }^{42}$

Because of the increased maternal morbidity in women attempting TOLAC, the identification of factors associated with failed TOLAC is mandatory in selecting patients who may be considered as VBAC candidates. The identification of factors associated with failed TOLAC is significant as well, to minimize the costs of both ERCD and also failed TOLAC since the costeffectiveness of TOLAC is dependent on the likelihood of VBAC. ${ }^{12,43}$

For all these reasons, it is important to know how to counsel women who have had a previous CS in their subsequent pregnancies regarding the route of delivery and for this purpose, a lot of studies have been done looking for the way to study the likelihood to have a successful delivery after a CS and to allow an accurate prediction of the probability of a uterine rupture.

\section{Prediction of Successful Delivery after CS}

As it is seen before, after the first cesarean delivery, a pregnant woman has to choose between an ERCD and a TOLAC to achieve VBAC.

\section{Risk Factors Predictive of TOLAC Success and Failure}

A meta-analysis performed in 2010 demonstrated that the two factors that increased the odds of VBAC were history of VBAC and history of vaginal delivery. Moreover, it showed that the most important factor associated with failed TOLAC was a prior cesarean delivery for a recurring indication, such as failure to progress. Even though other factors played a role, these were not as strongly associated with failed TOLAC.

The different characteristics that increase or decrease the probability of successful TOLAC and uterine rupture are listed in Table $2 .{ }^{44}$ Available evidence shows that the optimal candidates for successful vaginal delivery after CS are women with: ${ }^{12,40,42,45,46}$ 
Table 2: Factors related to successful TOLAC and uterine rupture

\begin{tabular}{|c|c|c|}
\hline Characteristics & OR for successful TOLAC & Risk of uterine rupture \\
\hline \multirow[t]{4}{*}{ Uterine incision } & Low transverse (success rate $60-80 \%$ ) & Low transverse (rate of $0.4-0.7 \%$ ) \\
\hline & & Two prior low transverse (rate of 1.59\%) \\
\hline & & Low vertical (rate of $1.05-2 \%$ ) \\
\hline & & Inverted T (rate of 4-9\%) \\
\hline \multirow[t]{3}{*}{ Prior vaginal delivery } & Prior vaginal delivery before cesarean (OR 3.9) & $\begin{array}{l}\text { Prior vaginal delivery before cesarean (OR } \\
0.26-0.62)\end{array}$ \\
\hline & Prior successful TOLAC (OR 4.76) & No prior vaginal delivery (rate of 1.1\%) \\
\hline & & Prior successful TOLAC (OR 0.52) \\
\hline \multirow{3}{*}{$\begin{array}{l}\text { Indication for the primary cesarean } \\
\text { delivery }\end{array}$} & Fetal malpresentation (success rate $75 \%$ ) & \\
\hline & $\begin{array}{l}\text { Non-reassuring fetal heart rate pattern (success rate } \\
60 \%)\end{array}$ & \\
\hline & $\begin{array}{l}\text { Failure to progress or cephalopelvic disproportion (suc- } \\
\text { cess rate } 54 \% \text { ) }\end{array}$ & \\
\hline \multirow[t]{3}{*}{$\begin{array}{l}\text { Spontaneous labor with a prior } \\
\text { cesarean vs induction vs ERCD }\end{array}$} & $\begin{array}{l}\text { Spontaneous labor (OR 1); cervical examination }<4 \mathrm{~cm} \\
\text { (OR 2.56) }\end{array}$ & Spontaneous labor (rate of $0.8 \%$ ) \\
\hline & & Induction (rate of 1.5\%) \\
\hline & Induction of labor (OR 0.5) & ERCD (rate of $0.022 \%)$ \\
\hline Fetal weight & $>4,000 \mathrm{~g}(\mathrm{OR} 0.55)$ & $\begin{array}{l}>4,000 \mathrm{~g} \text { and no prior vaginal delivery (rate } \\
\text { of } 3.6 \% \text { ) }\end{array}$ \\
\hline \multirow[t]{5}{*}{ Demographic factors } & Non-Hispanic Caucasians (OR 1) & \\
\hline & African Americans (OR 0.69) & \\
\hline & Hispanics (OR 0.65) & \\
\hline & $\mathrm{BMI}>30(\mathrm{OR} 0.55)$ & \\
\hline & $\begin{array}{l}\text { Maternal height (for each } 5 \mathrm{~cm} \text { maternal height in- } \\
\text { crease, OR 1.33) }\end{array}$ & \\
\hline \multirow[t]{2}{*}{ Prior uterine rupture } & & Prior uterine rupture (rate of $6 \%$ ) \\
\hline & & $\begin{array}{l}\text { Prior rupture involved the upper uterine } \\
\text { segment (rate of } 32 \% \text { ) }\end{array}$ \\
\hline
\end{tabular}

Factors related to the probability of successful TOLAC and uterine rupture

- One prior low transverse uterine incision.

- A successful vaginal delivery before or after their primary cesarean delivery.

- A non-recurrent indication for their primary cesarean delivery.

- Spontaneous labor on admission to the labor unit.

Several calculators are available for predicting the chance of VBAC. However, they have several limitations including no calculator that has been prospectively validated to determine if its use affects patient decision-making or reduces maternal morbidity; no calculator has been validated in women with multiple gestations; no calculator predicts patient-specific morbidity rates as the risk of uterine rupture.

On the other hand, some predictive models have been developed, yielding a score that correlates with the likelihood of achieving a vaginal birth: ${ }^{42,47,48}$

- Shared decision-making model $\rightarrow$ this model consists of using a VBAC calculator as part of the shared decision-making process. This model incorporates many of the standard risks and benefits of a trial of labor $v s$ ERCD and also an individual predicted chance of VBAC.

- Vaginal birth after cesarean score at admission for delivery model $\rightarrow$ it consists of stablishing a score at admission for prediction of VBAC at that time. This score is based primarily on the cervical examination (Bishop score) at the time of admission, but adding other factors like history of vaginal delivery, prepregnancy BMI, the non-recurring indication of $C S$, and maternal age at delivery. The VBAC score is then correlated with the probability of VBAC.

- Smith model $\rightarrow$ this model calculates the probability of cesarean for a specific patient by multiplying the odds of cesarean for other patient's characteristics like height, age, previous vaginal birth, weeks of gestation, method of induction, and fetal sex. Moreover, it provides an estimate of uterine rupture.

- Model for preterm pregnancies $\rightarrow$ this is the only model that predicts the likelihood of VBAC in women who are going to deliver preterm. Factors associated with increased likelihood of VBAC are diabetes, greater cervical dilatation, history of vaginal birth, and history of VBAC. Factors associated with a decreased likelihood of VBAC are induction of labor, recurring indication for prior cesarean, and hypertensive disease. The overall predictive capability of the model is very good with an AUC of 0.80 .

\section{Prediction of Uterine Rupture}

As it is mentioned before, the risk of uterine rupture in laboring women with a previous cesarean delivery varies between $0.2 \%$ and $1.5 \%$ after induction of labor, compared to $0.5 \%$ and $0.8 \%$ in women with spontaneous labor after a previous CS. Uterine rupture requires immediate surgical intervention and its occurrence can result in severe morbidity and mortality for both mother and child.

Sonographic lower uterine segment thickness (distance from bladder wall to amnion) near term is inversely correlated with the risk of uterine rupture at delivery. Even though, there is no 
cut-off value usable in clinical practice in women with a scarred uterus. A systematic review of 21 studies could not determine an ideal cut-off and the authors concluded that a full lower uterine segment thickness cut-off of 3.1-5.1 $\mathrm{mm}$ and a myometrium thickness cut-off of 2.1-4.0 mm was reassuring that the scar would remain intact during a TOLAC (strong negative predictive value). At this cut-off, sensitivity for the occurrence of a uterine defect was $96 \%$ and specificity was $63 \%$. Moreover, they determined that a myometrium thickness cut-off between $0.6 \mathrm{~mm}$ and $2.0 \mathrm{~mm}$ provided a strong positive predictive value for the occurrence of a defect.

An ideal screening test to predict uterine rupture would require high levels of both sensitivity and specificity ( $\geq 90 \%)$. These data, therefore, show that there is no clear cut-off value for the ultrasonic measurement of the lower uterine segment in late pregnancy because of its insufficiently predictive value. ${ }^{45,49,50}$

Finally, some models for the prediction of uterine rupture have been developed using the same graphic nomogram used to establish the probability of achieving a VBAC after a TOLAC. However, the nomogram calibration demonstrated that the predicted probabilities of uterine rupture did not reflect accurately the empiric probabilities of the patients. Thus, the prediction models were neither accurate nor discriminating. ${ }^{45,47,51}$

This paper was previously published in Chervenak FA, Kupesic Plavsic S, Kurjak A. The Fetus as a Patient: Current Perspectives. New Delhi: Jaypee Brothers Medical Publishers, 2020: 263-274.

\section{References}

1. Gibbons L, Belizán JM, Lauer JA, et al., The Global Numbers and Costs of Additionally Needed and Unnecessary Caesarean Sections Performed per Year: Overuse as a Barrier to Universal Coverage. World Health Report 2010 Background Paper, 30.

2. Moraitis AA, Oliver-Williams C, Wood AM, et al. Previous caesarean delivery and the risk of unexplained stillbirth: retrospective cohort study and meta-analysis. BJOG 2015;122(11):1467-1474. DOI: 10.1111/1471-0528.13461.

3. O'Neill SM, Kearney PM, Kenny LC, et al. Caesarean delivery and subsequent stillbirth or miscarriage: systematic review and meta-analysis. PLoS ONE 2013;8(1):e54588. DOI: 10.1371/journal. pone. 0054588 .

4. Gurol-Urganci I, Bou-Antoun S, Lim CP, et al. Impact of caesarean section on subsequent fertility: a systematic review and metaanalysis. Hum Reprod 2013;28(7):1943-1952. DOI: 10.1093/humrep/ det130.

5. Gurol-Urganci I, Cromwell DA, Mahmood TA, et al. A populationbased cohort study of the effect of Caesarean section on subsequent fertility. Hum Reprod 2014;29(6):1320-1326. DOI: 10.1093/humrep/ deu057.

6. Downes KL, Hinkle SN, Sjaarda LA, et al. Previous prelabor or intrapartum cesarean delivery and risk of placenta previa. Am J Obstet Gynecol 2015;212(5):669.e1-6. DOI: 10.1016/j.ajog.2015.01.004.

7. Silver RM, Barbour KD. Placenta accreta spectrum: accreta, increta, and percreta. Obstet Gynecol Clin North Am 2015;42(2):381-402. DOI: 10.1016/j.ogc.2015.01.014

8. Rosenberg T, Pariente G, Sergienko R, et al. Critical analysis of risk factors and outcome of placenta previa. Arch Gynecol Obstet 2011;284(1):47-51. DOI: 10.1007/s00404-010-1598-7.

9. Odibo A, Cahill A, Stamilio D, et al. Predicting placental abruption and previa in women with a previous cesarean delivery. Am J Perinatol 2007;24(5):299-305. DOI: 10.1055/s-2007-981430.

10. Rouse DJ, MacPherson C, Landon M, et al. Blood transfusion and cesarean delivery. [erratum appears in Obstet Gynecol. 2006 Dec;108(6):1556] Obstet Gynecol 2006;108(4):891-897. DOI: 10.1097/01.AOG.0000236547.35234.8c.
11. Society of Obstetricians and Gyaencologists of Canada. SOGC clinical practice guidelines. Guidelines for vaginal birth after previous cesarean birth. No 155. Int J Gynaecol Obstet 2005;89(3):319-331. DOI: 10.1016/j.ijgo.2005.03.015.

12. Guise JM, Eden K, Emeis C, et al. Vaginal birth after cesarean: new insights. Evid Rep Technol Assess (Full Rep) 2010(191):1-397.

13. Guise JM, Denman MA, Emeis $C$, et al. Vaginal birth after cesarean: new insights on maternal and neonatal outcomes. Obstet Gynecol 2010;115(6):1267-1278. DOI: 10.1097/AOG.0b013e3181df925f.

14. Shimonovitz S, Botosneano A, Hochner-Celnikier D. Successful first vaginal birth after cesarean section: a predictor of reduced risk for uterine rupture in subsequent deliveries. Indian Med Assoc J 2000;2(7):526-528.

15. Shipp TD, Zelop C, Cohen A, et al. Post-cesarean delivery fever and uterine rupture in a subsequent trial of labor. Obstet Gynecol 2003;101(1):136-139. DOI: 10.1097/00006250-200301000-00026.

16. Caughey AB, Shipp TD, Repke JT, et al. Rate of uterine rupture during a trial of labor in women with one or two prior cesarean deliveries. Am J Obstet Gynecol 1999;181(4):872-876. DOI: 10.1016/s00029378(99)70317-0.

17. Landon MB, Spong CY, Thom E, et al. Risk of uterine rupture with a trial of labor in women with multiple and single prior cesarean delivery. Obstet Gynecol 2006;108(1):12-20. DOI: 10.1097/01. AOG.0000224694.32531.f3.

18. Bujold E, Gauthier RJ. Risk of uterine rupture associated with an interdelivery interval between 18 and 24 months. Obstet Gynecol 2010;115(5):1003-1006. DOI: 10.1097/AOG.0b013e3181d992fb.

19. Kessous $R$, Sheiner $E$. Is there an association between short interval from previous cesarean section and adverse obstetric and perinatal outcome? J Matern Fetal Neonatal Med 2013;26(10):1003-1006. DOI: 10.3109/14767058.2013.765854.

20. Roberge S, Chaillet N, Boutin A, et al. Single- versus double-layer closure of the hysterotomy incision during cesarean delivery and risk of uterine rupture. Int J Gynaecol Obstet 2011;115(1):5-10. DOI: 10.1016/j.ijgo.2011.04.013.

21. Bujold E, Goyet M, Marcoux S, et al. The role of uterine closure in the risk of uterine rupture. Obstet Gynecol 2010;116(1):43-50. DOI: 10.1097/AOG.0b013e3181e41be3.

22. Bujold E, Bujold C, Hamilton EF, et al. The impact of a single-layer or double-layer closure on uterine rupture. Am J Obstet Gynecol 2002;186(6):1326-1330. DOI: 10.1067/mob.2002.122416.

23. Al-Zirqi I, Daltveit AK, Forsén $L$, et al. Risk factors for complete uterine rupture. Am J Obstet Gynecol 2017;216(2):165. DOI: 10.1016/j. ajog.2016.10.017.

24. Roberge S, Boutin A, Chaillet N, et al. Systematic review of cesarean scar assessment in the nonpregnant state: imaging techniques and uterine scar defect. Am J Perinatol 2012;29(6):465-471. DOI: 10.1055/s0032-1304829.

25. Vikhareva Osser O, Valentin L. Clinical importance of appearance of cesarean hysterotomy scar at transvaginal ultrasonography in nonpregnant women. Obstet Gynecol 2011;117(3):525-532. DOI: 10.1097/AOG.0b013e318209abf0.

26. Weinstein D, Benshushan $A$, Tanos $V$, et al. Predictive score for vaginal birth after cesarean section. Am J Obstet Gynecol 1996;174(1 Pt 1):192-198. DOI: 10.1016/s0002-9378(96)70393-9.

27. Lovell R. Vaginal delivery after caesarean section: factors influencing success rates. Aust N Z J Obstet Gynaecol 1996;36(1):4-8. DOI: 10.1111/j.1479-828x.1996.tb02910.x.

28. Landon MB, Grobman WA. What we have learned about trial of labor after cesarean delivery from the maternal-fetal medicine units cesarean registry. Semin Perinatol 2016;40(5):281-286. DOI: 10.1053/j. semperi.2016.03.003.

29. Timor-Tritsch IE, Monteagudo A, Cali G, et al. Easy sonographic differential diagnosis between intrauterine pregnancy and cesarean delivery scar pregnancy in the early first trimester. Am J Obstet Gynecol 2016;215(2):225. DOI: 10.1016/j.ajog.2016.02.028.

30. Calì G, Timor-Trisch IE, Palacios-Jaraquemada J, et al. Outcome of cesarean scar pregnancy: a systematic review and meta-analysis. 
Ultrasound Obstet Gynecol 2018;51(2):169-175. DOI: 10.1002/ uog. 17568 .

31. Birch Petersen K, Hoffmann E, Rifbjerg Larsen C, et al. Cesarean scar pregnancy: a systematic review of treatment studies. Fertil Steril 2016;105(4):958-967. DOI: 10.1016/j.fertnstert.2015.12.130.

32. Kanat-Pektas M, Bodur S, Dundar O, et al. Systematic review: what is the best first-line approach for cesarean section ectopic pregnancy? Taiwan J Obstet Gynecol 2016;55(2):263-269. DOI: 10.1016/j. tjog.2015.03.009.

33. Timor-Trisch IE, Cali G, Monteagudo A, et al. Foley balloon catheter to prevent or manage bleeding during treatment for cervical and cesarean scar pregnancy. Ultrasound Obstet Gynecol 2015;45(1):118123. DOI: 10.1002/uog.14708.

34. Maheux-Lacroix S, Li F, Bujold E, et al. Cesarean scar pregnancies: a systematic review of treatment options. J Minim Invasive Gynecol 2017;24(6):915-925. DOI: 10.1016/j.jmig.2017.05.019.

35. Green L, Knight M, Seeney F, et al. The epidemiology and outcomes of women with postpartum haemorrhage requiring massive transfusion with eight or more units of red cells: a national cross-sectional study. BJOG 2016;123(13):2164-2170. DOI: 10.1111/1471-0528.13831.

36. Oya A, Nakai A, Miyake $H$, et al. Risk factors for peripartum blood transfusion in women with placenta previa: a retrospective analysis. J Nippon Med Sch 2008;75(3):146-151. DOI: 10.1272/jnms.75.146.

37. Vintzileos AM, Ananth CV, Smulian JC. Using ultrasound in the clinical management of placental implantation abnormalities. Am J Obstet Gynecol 2015;213(4 Suppl):S70-S77.

38. Cheng KK, Lee MM. Rising incidence of morbidly adherent placenta and its association with previous caesarean section: a 15-year analysis in a tertiary hospital in Hong Kong. Hong Kong Med J 2015;21(6):511517. DOI: 10.12809/hkmj154599.

39. Jauniaux E, Bhide A. Prenatal ultrasound diagnosis and outcome of placenta previa accreta after cesarean delivery: a systematic review and meta-analysis. Am J Obstet Gynecol 2017;217(1):27-36. DOI: 10.1016/j.ajog.2017.02.050.

40. D'Antonio F, lacovella C, Bhide A. Prenatal identification of MAP using ultrasound: systematic review and meta-analysis. Ultrasound Obstet Gynecol 2013;42(5):509-517. DOI: 10.1002/uog.13194.

41. Edward Wells C, Gary Cunningham F, Choosing the route of delivery [internet]. Uptodate: Vincenzo Berghella; 2017 [reviewed
November 2017; consulted December 2017]. Available from: www.uptodate.com.

42. Rossi AC, Addario VD. Maternal morbidity following a trial of labor after cesarean section vs elective repeat cesarean delivery: a systematic review with meta-analysis. Am J Obstet Gynecol 2008;199(3):224-231. DOI: 10.1016/j.ajog.2008.04.025.

43. Torry de Metz. Use of calculators and models for predicting vaginal birth after a previous cesarean delivery [internet]. Uptodate:Vincenzo Berghella; 2017 [reviewed November 2017; consulted December 2017]. Available from: www.uptodate.com.

44. Eden KB, Mcdonagh M, Denman MA, et al. New insights on vaginal birth after cesarean: can it be predicted? Obstet Gynecol 2010;116(4):967-981. DOI: 10.1097/AOG.0b013e3181f2de49.

45. Daniels S, Ns D, Iglesias $S$, et al. Guidelines for vaginal birth after previous cesarean birth. 2005;155(147).

46. Landon BM, Heather $F$, Uterine rupture after previous cesarean delivery [internet]. Uptodate: Vincenzo Berghella; 2017 [reviewed November 2017; consulted December 2017]. Available from: www. uptodate.com.

47. Martel MJ, MacKinnon. No. 155-Guidelines for vaginal birth after previous cesarean birth. J Obstet Gynaecol Can 2018;40(3):e195-e207. DOI: 10.1016/j.jogc.2018.01.014

48. Macones GA, Cahill AG, Stamilio DM, et al. Can uterine rupture in patients attempting vaginal birth after cesarean delivery be predicted? Am J Obstet Gynecol 2006;195(4):1148-1152. DOI: 10.1016/j.ajog.2006.06.042.

49. Jastrow N, Gauthier RJ, Gagnon G, et al. Impact of labor at prior cesarean on lower uterine segment thickness in subsequent pregnancy. YMOB 2010;202(6):563.e1-563.e7. DOI: 10.1016/j. ajog.2009.10.894.

50. Kok N, Wiersma IC, Opmeer BC, et al. Sonographic measurement of lower uterine segment thickness to predict uterine rupture during a trial of labor in women with previous cesarean section: a metaanalysis. Ultrasound Obstet Gynecol 2013;42(2):132-139. DOI: 10.1002/ uog.12479.

51. Grobman WA, Lai Y, Landon MB, et al. Prediction of uterine rupture associated with attempted vaginal birth after cesarean delivery. Am J Obstet Gynecol 2008;199(1):30.e1-5. DOI: 10.1016/j.ajog.2008. 03.039. 